\title{
Announcement from the President
}

DOI: $10.1038 / \mathrm{sj} / \mathrm{sc} / 3101302$

\section{The new name: International Spinal Cord Society}

After discussion at the Annual General Meeting of the International Medical Society of Paraplegia (IMSoP) held during the Annual Scientific Meeting in Nottwil, Switzerland in September 2001, it was decided to change the name of the society to the 'International Spinal Cord Society (ISCoS)'. This is indeed an epochmaking decision, following the change of the name of the society's journal to 'Spinal Cord' in 1995. Consequently, not only does the new name reflect the very broad based functions and activities of the society, encompassing various problems and manifold aspects relating to traumatic and non-traumatic lesions of the spinal cord, the new name also allows the society to continue to grow in innovative ways true to the ideals of the organisation.

For a propitious start towards these objectives, we must continue to strive to guide ISCoS successfully through many more changes, including the following: (1) A multidisciplinary system to provide a high quality medical service; (2) A globalised research and development (R\&D) database to overcome spinal cord injury (SCI) and spinal cord disease (SCD); and (3) Worldwide provision to prevent SCI and SCD.

The key to the greater development of our society with the new objectives arising from the change of the society's name lies in the globalised intellectual and technological exchanges between clinicians and basic scientists as well as in the efficient use of each others institutes, facilities and equipment. While providing the national and international framework in education and research among ISCoS members, ISCoS must propel a new partnership between ISCoS members and basic scientists in the sectors of the spinal cord, working together as a new strategic global alliance. We are anticipating not only how much the global alliance will achieve in the radical treatment and prevention of conditions affecting the spinal cord and related organs and the maintenance of the general physical well being of the individual, but also what form of education and research will be set up by the global alliance to meet with the needs of younger members.

To carry out the creative R\&D activities as well as to encourage the active participation of younger members, we must create the research and education foundation as the most urgent task. Support for the foundation is found primarily in ISCoS members, but is also received from many others, including charitable funds and industries around the world.

It is hoped that the change in the society's name will act as an impetus to more advances based on basic and clinical science of spinal cord function, injury and disease. To promote the R\&D activities, I do emphasize once again the need to build and strengthen multidisciplinary and comprehensive education and research infrastructures.

In this era of great transition, the worldwide community is watching the actions of the professionals more closely and has greater expectations than ever before. We should bear this in mind as we embark with our lifelong partners to fulfil the goal of ISCoS. We need each of you, your ideas and your enthusiasm.

Takaaki Ikata President 